\title{
14. A CROSS-DISCIPLINARY ANALYSIS OF SCIENCE CLASSROOM DISCOURSE
}

\section{INIROIOL"IION}

There has been little research in the science education literature employing a cross-disciplinary approach to analyse the ways science classroom discourse mediates students" scientific meaning making. This study aims to fill this gap in the literature. It employs the Flow of Discourse (FOD) framework originating from sociocultural psychology and science education and the Systemic Functional Linguistic (SFL) framework orginating from sociolinguistics to enrich our understanding of complex classroom interactions.

The importance of classroom discourse in influencing science learning is emphasised in a sociocultural perspective on learning. A sociocultural perspective foregrounds the social interaction on the interpsychological plane that must take place prior to learning (Vygotsky, 1978, 1981). Language, by functioning as a tool for social interaction, performs an important mediating role in the learning of science (Scott, 1998; Wells, 1992; Wilson \& McMeniman, 1992). It follows that the ways classroom discourse are used to mediate students' scientific meaning making is an aspect of science education worthy of study.

Hicks (1995) suggested that research on how classroom discourse supports the construction of knowledge should draw upon research methodologies in a multidisciplinary fashion in order to study classroom discourse in its full complexity. Currently, little of this kind of research has been done. Our study aims to fill this "gap" by utilising perspectives derived from different disciplines-.. sociocultural psychology, science education, and sociolinguistics-and to test the feasibility and value of a cross-disciplinary approach. Moreover, Wells (1994) has previously argued that the contributions of Vygotsky and Halliday (in which the two frameworks are grounded) to the understanding of children's development of and through language are not only compatible but also complementary.

\section{THE ANAIYTICAL, FRAMEWORKS}

\section{Flow of Discourse}

Developed as part of "an established and continuing line of research work" (Scott, 1998; Mortimer. 1998; Mortimer \& Scott, 2000), the FOD framework provides a set of "analytical tools for reviewing and identifying the different hinds and patterns of classroom talk" (emphasis in original, Mortimer \& Scott, 2000, p. 126). 
The FOD framework is based on a Vygotskian approach, and focuses on the ways in which classroom discourse makes scientific knowledge available on the intermental (interpsychological) plane. Through the process of internalisation. individual students then develop understandings of scientific concepts on the intramental (intrapsychological) plane. Though the FOD framework makes visible the role of language in making scientific knowledge available on the intermental plane. it does not claim to reveal the extent to which individual students are able to internalise and understand the scientific concepts made available on the intermental plane.

The fiamework highlights three aspects of the discourse:

1. the content of discourse:

2. the form of utterances; and

3. the patterns in the llow of discourse.

In our study, analysis of the content of the diseourse led to the identification of separate learning goals for each phase of the lesson, based on the scientific knowledge that the teacher was trying to convey in that phase. Analysing the form of the utterances involved classifying those teacher and student utterances directly related to the learning goals of description, explanation. generatisation and inference. The "patterns in the flow of discourse" refers to the forms of pedagogical intervention that the teacher used; in other words, how the teacher"s discourse mediates the students" developing scientific understanding. An example of a pedagogical intervention would be: "Teacher guides students through the steps of an argument or explanation by means of a series of key questions" (Scott. 1997, p. 96$)$.

Scott (1997) identified live categories of pedagogical intervention (see Figure 1) and further grouped these into three strands: (1) developing scientific knowledge. (2) supporting student meaning making, and (3) maintaining the narrative. Together, the three strands constitute "a "Teaching Narrative" or teaching performance through which the teacher directs and sustains interactions to make the scientific view available to students" (Scott, 1998, p. 56).

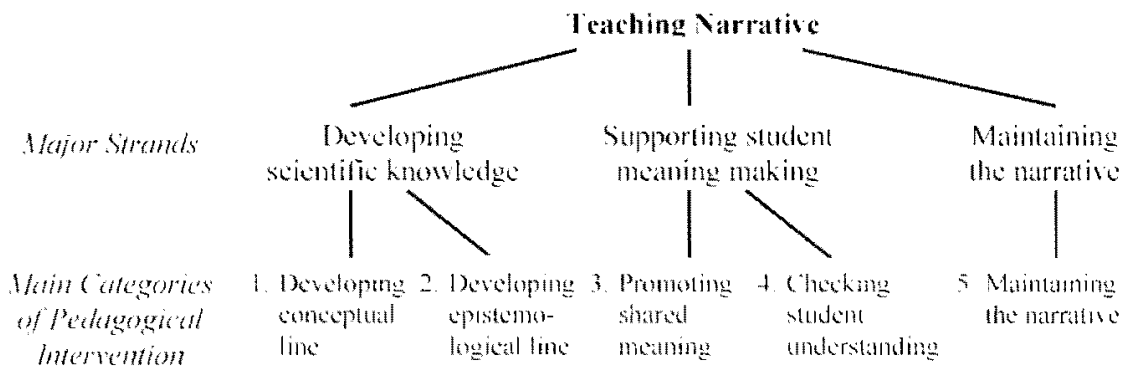

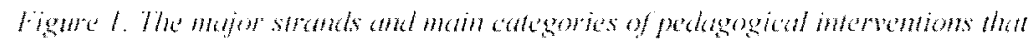

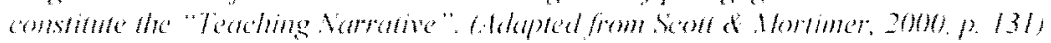


Reasons for using the FOD framewr. The FOD framework is particularly well-suited for analysing science lessons. The various forms of pedagogical intervention. used as coding categories in analysing the patterns in the flow of discourse. have been identified empirically from two cases studies, each comprising a sequence of science lessons on a particular topic (Scott, 1997). This empirical grounding provides specificity and validity in the context of science classrooms. By focusing on all three aspects of content, form and patterns of pedagogical interventions, the framework provides a comprehensive set of tools for analysing how classroom discourse supports the understanding of scientific knowledge.

\section{Systemic Fometional limgnistics}

The second framework used in this study derives from the SFL theory, which originated from the work of Michael Halliday and was subsequently expanded upon by other systemic linguists. This theory claims that all languages are functional: the function of language is to make meaning (Halliday, 1994), and how meaning is made can be explained in a non-arbitrary manner by reference to the functional components of the language. One of the goals of SFL theory is thus to explain the link between the organisation of the language in terms of its grammatical resources and the meanings realised by it. The SFL framework was chosen for this study because it has the potential to relate the use of grammatical resources to the process of constructing scientific meanings.

Halliday claimed that all languages are used to realise simultaneously three different kinds of meanings; experionial, textual and interpersonal. The experiential meanings, that is, those related to how speakers represent "what goes on around them and inside them" (1994, p. 106), are realised by the transitivity system'. The textual meanings, that is, the message of the communicative event, are in turn realised by the thematic system; while the interpersonal meanings, those involved in enacting social relationship, are realised by the mood system. Due to time constraints, the analysis in this study was restricted to only the transitivity and textual resources used by the teacher.

Reasoms for the we of the SFL frumerterk. The need for discourse analysis to be based on grammar is strongly advocated by llalliday, who argued that "a discourse analysis that is not based on grammar is not an analysis at all, but simply a rumning commentary on a text" (1994, p. xvi). As Halliday explained "without a theory of wordings - that is, a grammar there is no way of making explicit one's interpretation of the meaning of a text" (p. xvii), As the FOD framework is not based on the linguistic perspective. it does not allow for grammatical analysis of the discourse. Designed to explain the meanings of language at the lexicogrammatical level, the SFL is a concrete and comprehensive framework in which grammar has a central place in the interpretation and analysis of text. This study. however. does not claim nor aim to be a linguistic study of classroom discourse, 
but merely borrows from the SFL framework analytical tools that will allow us to investigate how language at the lexico-grammatical level mediates students" scientific meaning making.

\section{DATA}

The data was from the transcript of the audio and video recordings from the first half of a 1 -hour Chemistry lesson on rate of reaction. The class comprised 27 Secondary 4 (Grade 10) students, and was taught by a teacher with more than 6 years of teaching experience in a co-educational govermment school in Singapore. In this lesson episode. the students were expected to learn about the effects of particle size on rate of reaction and the explanation for these effects in terms of collision theory.

\section{RISUITS}

The two frameworks revealed different insights about the classroom discourse. Due to space constraints, only some of the findings in our study are presented below. A case is then made in the Discussion as to why and how the two frameworks provided complementary insights about the classroom discourse.

\section{What the FOD Framewerk Revealed Abou Classrom Discourse}

The teacher's two main goals for the lesson were to teach the effects of particle size on the rate of reaction and the explanation for the effects using collision theory. However, the content analysis revealed at least nine phases in the lesson. each with distinct learning goals (see Table 1). These represented the "building blocks" that the teacher used to achieve the two main content goals she had in mind.

Table 1. Learning goals for each phase

\begin{tabular}{|c|c|}
\hline Phatse & Leanning Goal \\
\hline $\mathbf{I}$ & To know the ellects of particle size on the rate of reaction. \\
\hline 2 & $\begin{array}{l}\text { To identity the conditions that were kept constant and the variable under } \\
\text { imvestigation in the two experiments carried out to deternine the effects of particle } \\
\text { size on rate of reaction. }\end{array}$ \\
\hline 3 & $\begin{array}{l}\text { To identify the diflerence in total surface area betwen magnesium ribbon and } \\
\text { powder as the reason lor their different rates of reaction with hydrochloric acid. }\end{array}$ \\
\hline 4 & To learn the type and shape of graph that can be obtained from such an experiment. \\
\hline 5 & $\begin{array}{l}\text { To determine the difference in gradient between the two graphs obtained from the } \\
\text { experiments and its interpretation in terms of rate of reation. } \\
\text { To draw the tangent at a specilie point on the grapls to determine the gradient. }\end{array}$ \\
\hline
\end{tabular}




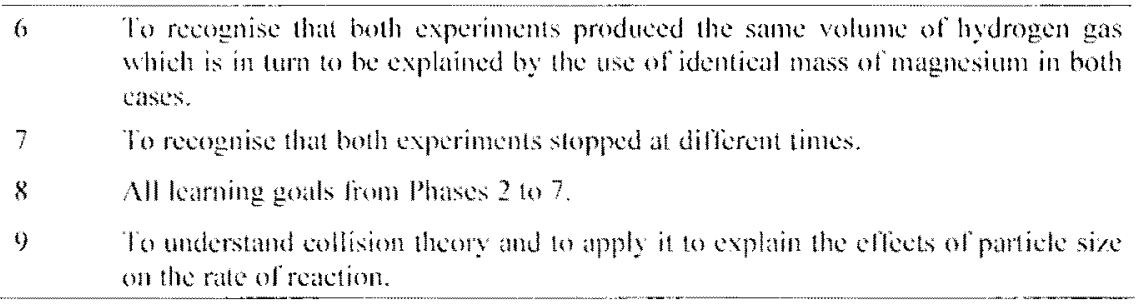

The forms of both teacher and student utterances was analysed in terms of four categories: description, inference, explanation and generalisation. The forms of utterance were closely related to the learning goals identified in each phase. In phases where the learning goals required students to "identify" or to "recognise" certain concepts. the utterances tended to be description; while those that required students to elaborate tended to be explanation. In the case of utterances that were classified as inference, these tended to be elicited in response to questions from the teacher that were not specific (such as the ways in which magnesium ribbon and magnesium powder were different, and the request for students to comment on the graplis).

Overall, this analysis revealed the shift in discourse from a generalisation of the effects of particle size on the rate of reaction, to a description of the conditions of experiments that determined these effects, to description and inference of these effects from the graphs, and finally to an explanation of these effects. It is possible that another teacher may introduce the collision theory first, so as to provide the mechanism for predicting the effects of particle size on the rate of reaction. Such a lesson would very likely take a form that is the reverse of this lesson. An overview of the sequence of main forms of utterances, therefore, indicates the direction in which the conceptual line is developed (see Mortimer \& Scott. 2000).

Both the analysis of the discourse content and the form of utterances informed and facilitated the identification of the pedagogical interventions adopted by the teacher. Generally, the patterns of pedagogical intervention were similar for all the nine phases. Each usually began with an instructional question, with which the teacher shaped the discourse towards achieving the learning goals of that plase. Frequently, one student would be selected to answer the question. This was followed by a series of questions from the teacher in response to the student's statement, either to shape the devclopment of the conceptual line or to check student understanding. The teacher would then "mark" the importance of ideas presented. Finally, the phase would round off with the teacher reviewing key ideas presented by providing a summary of the main ideas. The following transcript found in Phase 3 of the lesson illustrates this pattern:

T: $\quad$ Somcone stand up and tell me why is this magnesium ribbon and magnesium powderin what way are they different? llow does it

\section{Pedagogical intervention}

Tshaped the discourse with an instractional question. 
affect the rate of reaction here? That's goes to [pointing to one particular student] Yes!

Tim: The total surface area of the powder is greater.

T: The total surface area of the powder is greater because the powder is very?

Tshaped the discomse or checked stmknt molerwanding by asking a sures of antestions.

SS: Small.

T: Fine and small. So it has got a larger?

Thaked the importance of ilea.

SS: Surlace area.

T: Total surface area. What about your magnesim ribbon?

Tim: (It has a smaller surface area) [Mumbling]

$\mathrm{T}$ : Also got small surface area. Because it is one whole one whole?

S: Mass.

T: Piece. Yes. So over here in Experiment-1. I use Treviewed key ideas. a magnesium ribbon and over here in mag. or Experiment-2, okay. I use a magnesium powder. So according to him, a powder will have a smaller particle size. Am I right? Smaller size and it will expose a larger surface area. Whereas a ribbon, the amount of surface area exposed will be lesser, all right.

Of the three aspects of discourse in the FOD framework, this aspect was the most useful in revealing the ways discourse was used by the teacher to mediate students" scientific meaning making. Specifically, it reveals the discursive strategies used by the teacher in making scientific meanings available on the intermental plane and in guiding students to make sense of these meanings. The former was mainly achieved by those pedagogical interventions classified under the strand of devetoping scientific knowledge (see Figure 1), whereas the latter was achieved by those classified under the strand of supporting studem meaning making and mainiaining the narrative (see Scott, 1997).

The analysis also revealed the implicit epistemology of the scientific knowledge that was presented. The few pedagogical interventions that involved the development of the epistemological line emphasised the importance of experiments in validating the effects of particle size on rate of reaction, and the need for control of the experimental conditions by keeping all conditions constant exeept the variable under investigation. 
While those interventions frequently used by the teacher reveals something about the nature of the lesson, the interventions that were not used are also significant in indicating what the lesson was not about. Of those pedagogical interventions identified by Scott (1997) as involved in the development of a conceptual line, those not used in this lesson included:

1. teacher differentiates ideas; and

2. teacher offers a direct choice between ideas.

The lack of use of these two pedagogical interventions suggests that the teacher's intention was not so much to gather students" everyday perspectives. Instead, she appeared to be interested in consolidating and reinforcing the seientific perspective that they were expected to have internalised from previous lessons, and possibly to reshape some misconceptions that they might have had with regard to the topic. This interpretation is also supported by the observation that the students appeared to possess some understanding about the topic prior to this lesson. Other evidence for this was the lack of variety in the answers given, even when several students responded simultaneously. Consequently, the teacher did not check for consensus of ideas (another pedagogical intervention identified by Scott, 1997) since there was little need, if any.

In summary, the three aspects of the discourse addressed in the FOD analysis reveal the overall instructional approach taken by the teacher to mediate students" understanding of the two main goals for this lesson. The analysis shows what scientific meanings the teacher made available on the intermental plane and how she did so, as well as how she guided students to make sense of these meanings.

\section{What the SFL Framensonk Reveated Aboun Chassom Discomse}

The SFL analysis revealed the grammatical resources used in the lesson as well as how they were used. For example, the teacher's use of transitivity resources indicates that scientific knowledge was made available on the intermental plane mainly through the use of relational processes ${ }^{2}$. Specifically, attributive processes were used mainly to describe and compare scientific concepts, whereas identifying processes were used to classify, define, emplasise and paraphrase scientific knowledge. In contrast. the teacher used non-relational processes mainly to guide students to make sense of the scientific meanings. For example, she used mental processes to engage students in thinking, behavioural processes to direct students' attention to a particular subject of discussion, and verbal processes to elicit students' knowledge of the subject of discussion.

Through her choice of processes, the teacher guided students to make sense of the scientific meanings. She tended to use processes that were relatively simple and concrete. This facilitated students comprehension of both the teacher's instructions and the scientific conceptual knowledge made available on the intermental plane. In particular, she used concrete behavioural processes, such as "look", "tell" and "see" to metaphorically realise higher cognitive stances ("analyse". "deduce" and "know", respectively) that were expected from students, such as when the teacher asked the students, "What can you tell from this graph 
here?" or "How can you tell that the rate of Experiment 1 is faster than Experiment 2?" These "behavioural" processes, being concrete and familiar to students, provided a stepping stone to higher level thinking (see Frydenberg. 1997). However, persistent use of them without explicit flagging of the higher cognitive stances involved, could mean that students are not exposed to those congruent cognitive processes such as analysing, deducing and inferring. Consequently, students may not even realise that what they are doing routinely in class is just that. and may remain clueless about how to answer assessment-type questions that require them to analyse, deduce or infer. when what is required from them is exactly what they were doing in class.

The transitivity analysis also showed that the teacher had a tendency to use the first person "me" as the Receiver rather than "us". This suggests that her intention of getting students to respond to her questions was more to check and evaluate their understanding than to enable the sharing of their knowledge with the class. The Attribute that described the Carrier in Attributive clauses was realised mainly by comparative adjectives, such as "larger". "smaller". "faster", "slower". "steeper" or "higher". This feature of the Attribute reveals much about the epistemology of the scientific knowledge presented. It indicates that scientific concepts were described in relation to another entity of a similar form. For example, "Experiment-2 is faster than Experiment-1", the Carrier, "Experiment-2" was described in relation to another experiment by the Attribute "faster than Experiment-1". In other words, the scientific knowledge was realised by comparison. Overall, the effects of particle size on rate of reaction were inferred by comparing and contrasting two forms of magnesium of different particle size.

Nominalisation (the conversion of a process into a nominal group), which occurs frequently in written scientific discourse. has the effect of condensing multiple meanings into a single phrase (Halliday \& Martin, 1993), which the reader has to unpack. The few instances of nominalisation used by the teacher (e.g., rate of reaction and chances of collision between the reacting particles) suggest that minimal unpacking of meanings was required by the students. In other words. students required little processing of the discourse in order to access the scientific meanings presented. As nominalisation tends to reconstruct "a world made up of things", its infrequent use also suggests that the teacher was in fact constructing a "world of happening events with things taking part in them" (Halliday, 1993. p. 82). The latter is a world that students tend to be more familiar with. This is well exemplified by the high frequency of material processes to realise human actions. and even a conceptual world of chemical entities in constant motion.

Analysis of the thematic resources used by the teacher showed frequent use of conjunctive adjuncts as textual themes. This suggests that the teacher was making explicit the interrelationship between concepts, an important component of scientific understanding. The appropriate and effective use of such textual themes is important if students are to understand the link between the various scientific concepts. However, the same cannot be said about the students" discourse. Conjunctive adjuncts were absent in the students' responses, except for one. 
Interestingly, this student's use of conjunctive adjuncts was inappropriate, but this was not commented on by the teacher.

$\mathrm{T}$ : How can you use collision theory to explain this? Roy.

Roy: When the magnesium is in powder form and it has a larger surface area and the chances that the hydrochloric molecule, the acid molecule, can collide with the magnesium molecules

T: 15 ?

Roy: Higher.

$\mathrm{T}$ : Higher. Okay.

Though Roy was obviously trying to construct a cause-and-effect relationship between the concepts that would be more appropriately expressed by the use of conjunctions such as "because" or "so", he used "and", which is an additive type of conjunction. The lack of and imappropriate use of these conjunctions in Roy's answer implies that students may be handicapped in their use of suitable conjunctions to construct expressions that show the interrelationship between scientific concepts appropriately. In fact, the teaching of the appropriate use of conjunctive adjuncts is often non-existent in science teaching but, we would argue, it ought to be a significant aspect. After all, the interrelationship between scientific concepts is an important component of scientific understanding. If teachers are aware of the significant role these conjunctive adjuncts play in constructing the interrelationship between concepts, and if they could in turn highlight them on the intermental plane, it might just go a long way in helping students to see the connections between the various concepts.

The teacher also used thematic resources to guide the students in making sense of scientific meanings. For example, she consistently used continuity adjuncts (e.g., "okay", "yes" and "now") to mark the boundaries between phases, suggesting that consciously or otherwise she had made visible the rhetorical structure of the discourse. This explicit narking of phase boundaries helps students identify the shifts in learning focus. The teacher"s frequent selection of "you" and "we" as participant-related topical themes also realised the students as active participants in the discussion and served to engage their attention. Furthermore, the teacher used "you" to realise the students as acting the part of reacting particles. This had the effect of making science come alive, as the students were cast as direct "participants" in the microscopic world of chemical particles. Lastly, the use of a consistent pattern of thematic development in most phases of the lesson also helped the students to focus their attention and to follow the discussion more easily. 


\section{Conplemsntaly Insights from the Two Framerouks}

There is at least one similar insight about the discourse as revealed by the different frameworks. Both frameworks highlight the interactive but authoritative nature of the discourse (see Mortimer \& Scott, 2000). In other words, the discourse was not a "one-man show" but involved multiple voices interacting with the teacher as she shaped the discourse through a series of instructional questions. Nonetheless, the discourse was not a "free for all" either. In fact. the teacher maintained control throughout allowing little opportunities for the discourse to go off course.

The main value of this cross-disciplinary approach, however. lies mainly with the different insights as revealed by the two frameworks. Though the insights about the classroom discourse are different, the findings from one framework do not contradict those from the other. In fact, we would argue that the insights gained from the two analyses are complementary. For example, while the pedagogical interventions (FOD tramework) identify what the teacher was doing by means of discourse and her purpose for doing them, the process types (SFI, fromework) used by the teacher reveal the behaviour. thinking and action expected of the students. Each framework highlights different features of the discourse and different aspeets of the epistemology of the scientific knowledge that was developed in this lesson. Fundamentally. the FOD framework revealed the instructional approach adopted by the tacher to achieve the main goals of the lesson, while the SFL framework showed what grammatical resources were used by the teacher to mediate the students" understanding of the scientific concepts. In other words. the FOD framework provides the macro-view of what and how the teacher used the discourse to mediate students understanding while the SFL framework provides the micro-view of how language operates to achieve that.

Looking at the same discourse from two different perspectives throws the spotlight on different aspects of the discourse, so that the insights gained from one framework complement those from the other. In other words, the limitations of one framework are compensated for by the strength of another framework, and in the process, more elements of significance that exist in the complex classroom interaction are identitied. Moreover, as the two frameworks originated from different contexts - the FOD framework from a mainly science classroom context and the SFL framework from the general social context-they allow the discourse to be analysed from both within and outside a science educator's perspective. The SFL framework. in particular, highlights potential problems relating to the use of the discourse that would not normally be identified using a traditional science classroom-based approach. Conversely, the use of the fOD framework complements the grammatical analysis of the discourse by suggesting the range of discursive strategies teachers have at their disposal. Furthermore. from our experiences. the insights gained from one framework stimulated and provided further impetus to the analysis using the other. Overall, these differences in insights complement each other and provide a more comprehensive view of the 
ways in which classroom discourse was used to mediate students' scientific meaning making.

\section{Implications for the Analysis of Classoom Discourse}

Understanding the usefulness of each framework allows us to see how each analytical tool can inform us about the classroom discourse. This knowledge is important as it helps determine which set of analytical tools one should use to investigate a particular research problem. For example, if the foeus is on how classroom discourse impacts students" abilities to answer test questions, the SFL framework would provide a useful set of analytical tools to study the grammatical resources the teacher used, which would very likely influence what students would use in their answers. On the other hand, if the focus is on how different teachers use discourse differently to develop students" conceptual understanding, the FOD framework would provide a useful alternative to study the instructional approach adopted by them. Different aspects of discourse affeet students in different ways and for dilierent reasons. It is therefore important that the most appropriate tools are used to study a particular research problem.

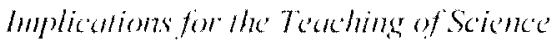

This study has underscored the important role that language plays in the mediation of scientitic understanding, and suggests that classroom discourse can both facilitate and constrain students' developing understanding of scientific concepts and their acquisition of the social language of science. Consequently, one way to improve students" achievement in science is by attending to the classroom discourse, particularly the discursive strategies and grammatical features of the language adopted by teachers.

Teachers themselves might even conduct similar studies. Such studies may heighten teachers awareness of the role of language in the leaming of science. It also potentially allows for the expansion of discursive strategies (e.g., in the form of pedagogical interventions) that teachers can use to develop classroom discourse in order to more effectively develop students" scientific understanding. In the words of Mortimer and Scott, "teachers can only begin to develop and extend the range of speech genres which they draw upon in the classroom when they become aware of the nature of their present performance" $(2000$, p. 141$)$.

\section{NOIIS}

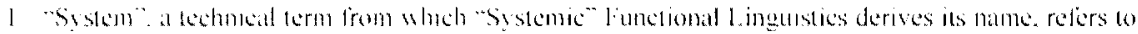

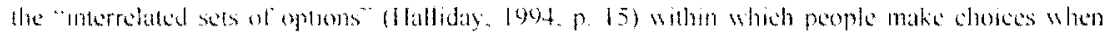

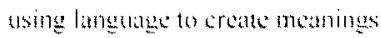

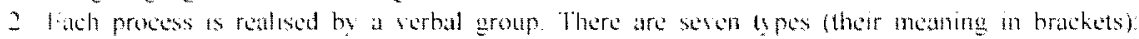

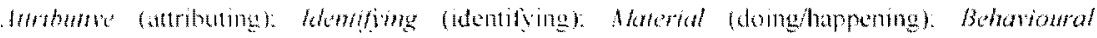

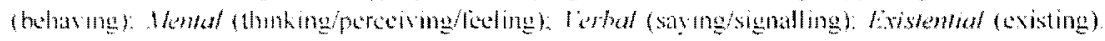

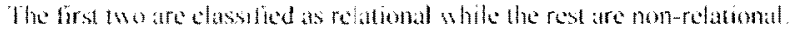




\section{RIFERIENCIS}

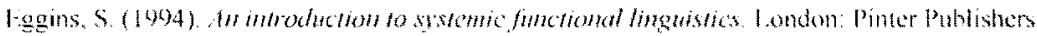

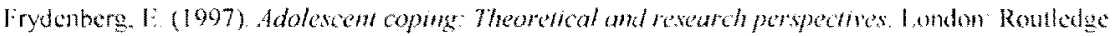
llalliday. M. A K (1993) Some grammatiod potbems in scientilic linglish. in M. A. K. Halliday $\&$

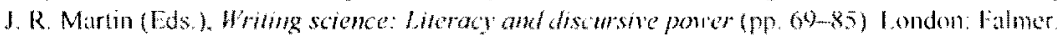

Halliday. M ^ K (1994), An introduction fo finchonal grammar (2nd od.). London: Edward Amotd.

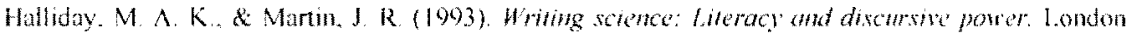
Falmer.

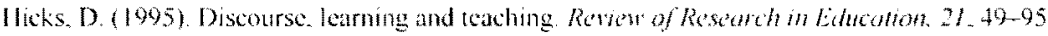

Mortimer, E. F. (1998). Multurotedness and unirocality in classoom discours: An example from theory of matter. Internationat lom at Science liducation. 20(1).67-82.

Mortimer. E. \& Scott. P. (2000). Analysing Discourse in the Seience Classroum. In R. Millar. I. I.weh.

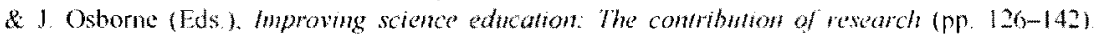
Buckingham, UK: Open University Press.

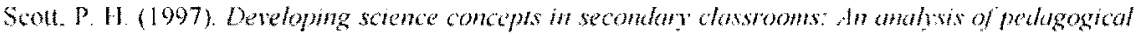
interactions from a Vyghkiam perspective. Unpublished doctoral thesis Unisersty ofleeds. UK

Soot. 1. (1998). Teacher talk and meaning making in science classrooms: $A$ Vygotskian analysis and review. Shathes in Science buacaton, 32.45-80.

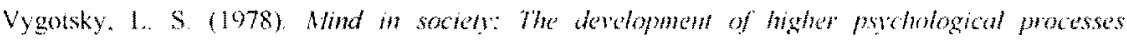
Canbridge, MA: llarvard Universily Press.

Vygotsky, L. S (1981) The instrumental method in psychology (I V. Wertsch, Trans). In $3 . V$ Wertsch (Ld.). The concept of activity in Sonte psichology (21) ed. pp. 134-143) New York M. E. Sharpe

Wels, G (1944). The complementary contributions of llallday and Vygotshy to a "language-based

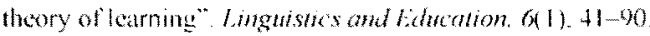

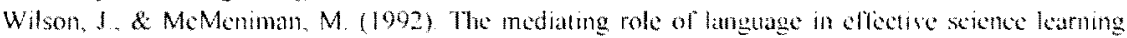

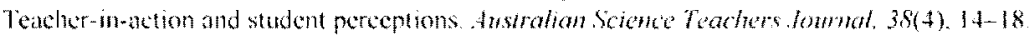

\section{AFHLINTIONS}

Suah Lay Hoon

National Instihte of Education,

Nanvang Technological University:

Singapore

Christina Harl

University of Melboume,

Australia 


\section{University Library}

\section{- M M I E R R V A gateway to Melbourne's research publications}

Minerva Access is the Institutional Repository of The University of Melbourne

Author/s:

SEAH, LH;HART, C

Title:

A Cross-Disciplinary Analysis of Science Classroom Discourse

Date:

2006

Citation:

SEAH, L. H. \& HART, C. (2006). A Cross-Disciplinary Analysis of Science Classroom

Discourse. Bokhorst-Heng, W (Ed.). Osborne, M (Ed.). Lee, K (Ed.). Redesigning Pedagogy:

Reflections on Theory and Praxis, (1), pp.191-204. Sense Publishers.

Persistent Link:

http://hdl.handle.net/11343/30679 